\title{
Five-Year Survivors of Non-Small Cell Lung Cancer Patients with Positive Pleural Lavage Cytology
}

\author{
Masaki Tomita*, Takanori Ayabe, Eiichi Chosa, Kunihide Nakamura \\ Department of Surgery II, Faculty of Medicine, University of Miyazaki, Miyazaki, Japan \\ Email: ${ }^{*}$ mtomita@med.miyazaki-u.ac.jp
}

Received 12 December 2013; revised 10 January 2014; accepted 18 January 2014

Copyright (C) 2014 by authors and Scientific Research Publishing Inc.

This work is licensed under the Creative Commons Attribution International License (CC BY).

http://creativecommons.org/licenses/by/4.0/

(c) (i) Open Access

\begin{abstract}
Background: The pleural lavage cytology (PLC) for non-small cell lung cancer (NSCLC) patients has been reported as a significant prognostic factor. The aim of this study is to clarify the clinicopathological characteristics of 5 -year survivors of patients with positive PLC. Methods: Among 401 resected NSCLC patients, $30(7.48 \%)$ patients with positive PLC were reviewed retrospectively. Results: Only 7 of 30 patients $(23.3 \%)$ survived more than 5 -year. There were no differences in age, gender, histology, $\mathrm{pT}$ status and pN status between 5-year survivors and non-survivors. On the other hand, the serum carcinoembryonic antigen (CEA) level was significantly higher in non-survivors. Among these 5-year survivors, 4 of 7 patients died of NSCLC recurrences more than 5 years after surgery. Remaining 3 patients survived without cancer recurrences. Interestingly these 3 survivors had not received any adjuvant therapies after surgery. Conclusion: None of the 5-year survivor with positive PLC had high serum CEA level. Furthermore 5-year survival did not equal to cure in NSCLC patients with positive PLC.
\end{abstract}

\section{Keywords}

Pleural Lavage Cytology Positive; Non-Small Cell Lung Cancer; 5-Year Survivor

\section{Introduction}

Pleural lavage cytology (PLC) is the microscopic study of cells obtained from saline instilled into and retrieved from the chest cavity (in patients without preoperative pleural effusion) during surgery for non-small cell lung cancer (NSCLC). Since its first use in 1958 [1], several studies, including meta-analytical studies, have clearly

*Corresponding author.

How to cite this paper: Tomita, M., Ayabe, T., Chosa, E. and Nakamura, K. (2014) Five-Year Survivors of Non-Small Cell Lung Cancer Patients with Positive Pleural Lavage Cytology. Advances in Lung Cancer, 3, 21-25.

http://dx.doi.org/10.4236/alc.2014.31003 
demonstrated a link between the presence of malignant cells in PLC and poor prognosis [2]-[11]. These concluded that positive PLC is a strong prognostic factor for survival.

However, some patients with positive PLC can survive more than 5-year. Therefore, in the present study, we examined the clinical characteristics of 5-year survivor with PLC positive NSCLC patients.

\section{Patients and Methods}

Consecutive NSCLC patients who had undergone surgical resection and pleural lavage cytology from 2000 through 2007 at University of Miyazaki Hospital were included in this study. There were 462 NSCLC patients who received complete resection. Following patients were excluded: 7 died of other diseases, 11 were lost to follow-up and 43 were not performed PLC. Therefore remaining 401 NSCLC patients were included in this study. PLC was performed as described before [8] Briefly, immediately following thoracotomy and prior to any further manipulation of the pulmonary parenchyma, the pleural cavity was carefully washed with $200 \mathrm{ml}$ of physiologic saline solution. The fluid was irrigated over the visceral and parietal pleura. The fluid was placed in a glass bottle containing heparin and centrifuged at $1500 \mathrm{rpm}$ for 5 minutes. The sediment was stained using Giemsa and Papanicolaou methods. Cytologic results were divided into two categories: negative and positive. Papanicolaou classes I, II, and III were regarded as negative; classes IV and V were considered positive. The PLC positive patients were included in this study.

Pathological (p) tumor-node-metastasis (TNM) staging was recorded in all patients based on the 7th edition of the American Joint Committee on Cancer (AJCC)/Union for International Cancer Control (UICC) classification. Follow-up information, including cause of death, was ascertained through a review of clinic notes and direct or family contact. Fischer's exact test with Yates' correction was used to correlate clinicopathological parameters. The survival curves of the patients were plotted by using the Kaplan-Meier method and analyzed using the log-rank test. Cox regression hazard model was used for univariate analysis. Statistical calculations were conducted with JMP (SAS Institute Inc. Cary, NC, USA) and values of $p$ less than 0.05 were accepted as being significant.

\section{Results}

Positive PLC findings were present in 30 of 401 patients. The baseline characteristics of PLC positive patients are summarized in Table 1 . There were 20 men and 10 women. Among PLC positive patients, there were only 7 of 30 patients who survived more than 5 years. The comparison of the clinicopathological characteristics between 5-year survivors and others was shown in Table 1. We failed to find any differences in age, gender, histology, $\mathrm{pT}$ status and $\mathrm{pN}$ status between 5-year survivors and non-survivors. Moreover postoperative adjuvant therapy was not related to 5-year survival. On the other hands, the serum carcinoembryonic antigen (CEA) level was significantly different between 5-year survivors and non-survivors. Figure 1 showed the survival curve based on serum CEA level. Preoperative high serum CEA level was found to be a significant prognostic factor in patients with positive PLC $(p<0.0001)$. The 5-year survival rate was $0 \%$ for patients with a high serum CEA level and positive PLC.

Among these 5-year survivors, 4 of 7 patients had recurrences and died of NSCLC at 66, 75, 78 and 101 months after surgery (shown in CEA normal group of Figure 1). Among these 4 patients, 3 patients were detected brain metastasis at 4 year, 5.5 year, 6 year after surgery, and other 1 patient had meningeal carcinomatosis at 4.5 year after surgery. The Remaining 3 of 75 -year survivors were alive without cancer recurrences. Interestingly our 3 survivors had not received any adjuvant therapies after surgery.

Although the number of patients in the present study is small, we also examined univariate analysis. The result of univariate analysis (Table 2) also showed the prognostic significance of serum CEA level. Other fac- tors did not related to patients' survival for patients with positive PLC.

\section{Discussion}

The present result showed that the ratio of positive PLC patients was $7.48 \%$ (30/401). The frequency of positive results in the literature varies according to amount of solution used, timing of the procedure, and the center, but in general is less than $10 \%$ in the larger published series [2]-[11].

The 5-year survival rate was $23.3 \%$ for the patients with positive PLC, and the survival curve was similar to 
Table 1. The baseline clinicopathological factors.

\begin{tabular}{|c|c|c|c|c|}
\hline & & 5-year survivor & Non survivor & $p$ Value \\
\hline \multirow[t]{2}{*}{ Age } & $<65$ & 2 & 7 & 0.706 \\
\hline & $\geq 65$ & 5 & 16 & \\
\hline \multirow[t]{2}{*}{ Gender } & Male & 4 & 16 & 0.879 \\
\hline & Female & 3 & 7 & \\
\hline \multirow[t]{2}{*}{ Histology } & Adeno & 6 & 18 & 0.914 \\
\hline & Others & 1 & 5 & \\
\hline \multirow[t]{2}{*}{ pT status } & pT1 & 3 & 5 & 0.536 \\
\hline & pT2-4 & 4 & 18 & \\
\hline \multirow[t]{2}{*}{ pN status } & pNO & 6 & 12 & 0.252 \\
\hline & pN1-2 & 1 & 11 & \\
\hline \multirow[t]{2}{*}{ CEA } & Normal & 7 & 7 & 0.005 \\
\hline & High & 0 & 16 & \\
\hline \multirow{2}{*}{$\begin{array}{l}\text { Adjuvant } \\
\text { therapy }\end{array}$} & Performed & 3 & 19 & 0.111 \\
\hline & Not performed & 4 & 4 & \\
\hline
\end{tabular}

CEA: carcinoembryonic antigen.

Table 2. Univariate analysis.

\begin{tabular}{ccccc}
\hline & Favorable & Unfavorable & Risk Ratio & 95\% CI \\
\hline Age & $<65$ & $\geq 65$ & 1.017 & $0.414-2.275$ \\
Gender & Female & Male & 0.563 & $0.231-1.253$ \\
Histology & Adeno & Others & 0.469 & $0.195-1.300$ \\
pT status & pT1 & pT2-3 & 0.553 & $0.201-1.300$ \\
pN status & pN0 & pN1-2 & 0.601 & $0.267-1.360$ \\
CEA & Normal & High & 0.213 & $0.079-0.538$ \\
\hline
\end{tabular}

CI: confidence interval; CEA: carcinoembryonic antigen.

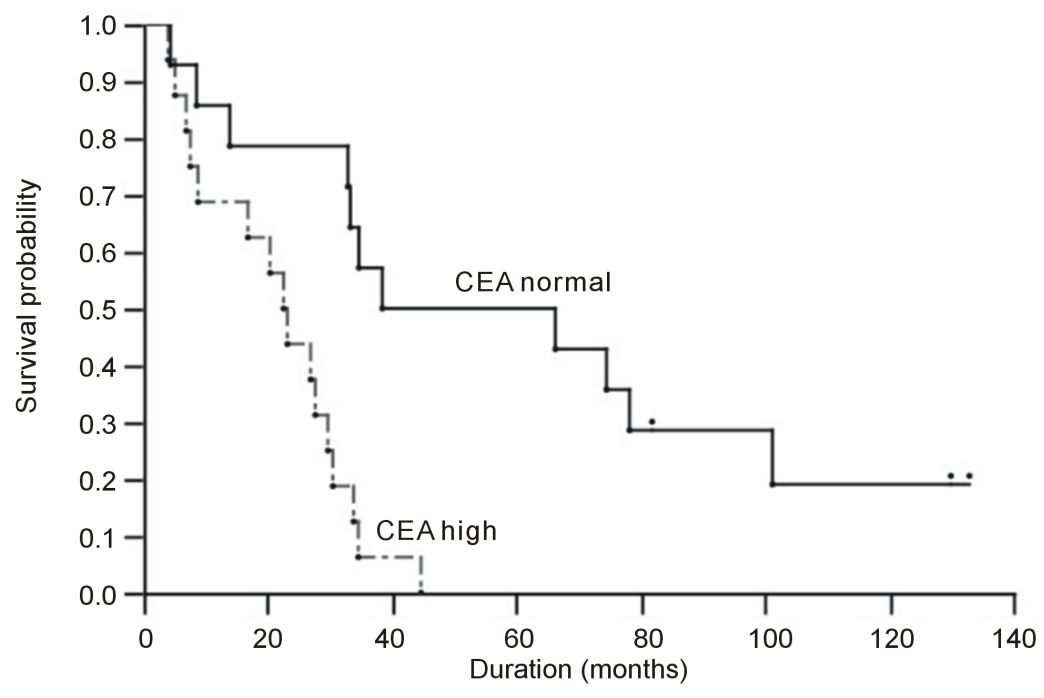

Figure 1. Survival of patients based on their preoperative serum CEA. 
that for patients with advanced disease. Kondo and colleagues [2] reported that patients with positive PLC showed survival equal to that in patients with stage IIIB or IV. Our result was similar to these findings. The reason for poor survival of patients with positive PLC has been largely unknown. It is considered that positive PLC might be a possible indicator of the initial stage of carcinomatous pleuritis. However Satoh and colleagues [10] analyzed recurrence patterns in patients with positive PLC results and reported that $72 \%$ had distant metastasis. Therefore positive PLC might reflect not only initial stage of carcinomatous pleuritis but also systemic disease.

We also showed that positive PLC patients with high serum CEA level had poorer survival. The CEA is one of the most common serum tumor markers in NSCLC patients. Many authors reported that NSCLC patients with a high serum CEA concentration have a poor prognosis [12]. Some previous studies examined the CEA level in pleural lavage fluid, and reported to be useful as prognostic markers of NSCLC after surgery [9] [13] [14]. However there were few reports about the combined examination of PLC findings and serum CEA level. In the present study, the 5-year survival rate was $0 \%$ for patients with a high serum CEA level and positive PLC. Kawachi and colleagues [11] also reported the similar results and they concluded that positive PLC alone may not be a contraindication for surgical resection, but patients who are complicated with a high CEA level preoperatively should receive special attention since no long-term survivors were observed.

It is generally accepted that 5-year survival is the most commonly used benchmark for long-term survival in NSCLC and has, at times, been equated with cure [15]. In our series, 4 of 7 patients with 5-year survivor had recurrences and died of NSCLC more than 5-year after surgery. Thus the 5-year survival rate of positive PLC NSCLC was $23.3 \%$, but 5-year survival without recurrences was only $10.0 \%$. This indicates that 5-year survival did not equal to cure in positive PLC NSCLC patients. Therefore long-term (more than 5-year) follow-up after resection should be performed.

Since the prognosis of patients with positive PLC is poor, several previous studies concluded that adjuvant systemic therapy may be necessary to improve outcome for patients with positive PLC [2]-[10]. However, to our knowledge, there are no data whether adjuvant systemic therapy might improve the prognosis of patients with positive PLC. Among 5-year survivors of positive PLC patients in our series, there were only 3 patients who survived without any recurrences. Interestingly these 3 survivors had not received any adjuvant therapies. However we do not believe that it denies the usefulness of adjuvant therapies. In our series, we did not perform the adjuvant therapies based on the PLC findings. Therefore our series are not suitable to examine the usefulness of the adjuvant therapies for positive PLC patients. In addition, the number of patients was quite small. Further clinical studies will be necessary to evaluate the efficacy of adjuvant therapy for positive PLC patients. An active form (deletion type of exon19 or mutation type of exon21) of Epidermal Growth Factor Receptor-Tyrosine Kinase (EGFR-TK) is well known to be predictive factor on the response to EGFR-TKI such as gefinitib and erlotinib [16]. In our series, we examined EGFR mutation for 7 of 30 patients, and we found that only 2 patients had EGFR mutation. These 2 patients received EGFR-TKI, and they died at 32 and 101 months after surgery. There is a possibility that EGFR-TKI might be also an effective drug for patients with both EGFR mutation positive and PLC positive.

\section{Conclusion}

In conclusion, none of the 5-year survivors with positive PLC had high serum CEA level. Furthermore 5-year survival did not equal to cure in PLC positive NSCLC patients.

\section{References}

[1] Spjut, H.J., Hendrix, V.J., Ramirez, G.A. and Roper, C.L. (1958) Carcinoma Cells in Pleural Cavity Washings. Cancer, 11, 1222-1225. http://dx.doi.org/10.1002/1097-0142(195811/12)11:6<1222::AID-CNCR2820110618>3.0.CO;2-U

[2] Kondo, H., Asamura, H., Suemasu, K., Goya, T., Tsuchiya, R., Naruke, T., Yamagishi, K. and Uei, Y. (1993) Prognostic Significance of Pleural Lavage Cytology Immediately after Thoracotomy in Patients with Lung Cancer. Journal of Thoracic and Cardiovascular Surgery, 106, 1092-1097.

[3] Higashiyama, M., Doi, O., Kodama, K., Yokouchi, H., Tateishi, R., Horai, T., Ashimura, J., Nagumo, S. and Naruse, Y. (1997) Pleural Lavage Cytology Immediately after Thoracotomy and before Closure of the Thoracic Cavity for Lung Cancer without Pleural Effusion and Dissemination: Clinicopathologic and Prognostic Analysis. Annals of Surgurgical Oncology, 4, 409-415. http://dx.doi.org/10.1007/BF02305554

[4] Ichinose, Y., Tsuchiya, R., Yasumitsu, T., Koike, T., Yamato, Y., Nakagawa, K., Tada, H., Yokoi, K., Nagai, K. and 
Kase, M. (2001) Prognosis of Non-Small Cell Lung Cancer Patients with Positive Pleural Lavage Cytology after a Thoracotomy: Results of the Survey Conducted by the Japan Clinical Oncology Group. Lung Cancer, 31, 37-41. http://dx.doi.org/10.1016/S0169-5002(00)00158-6

[5] Okada, M., Sakamoto, T., Nishio, W., Uchino, K., Tsuboshima, K. and Tsubota, N. (2003) Pleural Lavage Cytology in Non-Small Cell Lung Cancer: Lessons from 1000 Consecutive Resections. Journal of Thoracic and Cardiovascular Surgery, 126, 1911-1915. http://dx.doi.org/10.1016/S0022-5223(03)00715-3

[6] Enatsu, S., Yoshida, J., Yokose, T., Nishimura, M., Nishiwaki, Y., Shirakusa, T. and Nagai, K. (2006) Pleural Lavage Cytology before and after Lung Resection in Non-Small Cell Lung Cancer Patients. The Annals of Thoracic Surgery, 81, 298-304. http://dx.doi.org/10.1016/j.athoracsur.2005.06.073

[7] Lim, E., Clough, R., Goldstraw, P., Edmonds, L., Aokage, K., Yoshida, J., Nagai, K., Shintani, Y., Ohta, M., Okumura, M., Iwasaki, T., Yasumitsu, T., Okada, M., Mimura, T., Tsubota, N., Nakagawa, T., Okumura, N., Satoh, Y., Okumura, S., Nakagawa, K., Higashiyama, M., Kodama, K., Riquet, M., Vicidomini, G., Santini, M., Kotoulas, C., Hsu, J.Y. and Chen, C.Y. (2010) Impact of Positive Pleural Lavage Cytology on Survival in Patients Having Lung Resection for Non-Small-Cell Lung Cancer: An International Individual Patient Data Meta-Analysis. Journal of Thoracic and Cardiovascular Surgery, 139, 1441-1446. http://dx.doi.org/10.1016/j.jtcvs.2009.05.048

[8] Saso, S., Rao, C., Ashrafian, H., Ghaem-Maghami, S., Darzi, A. and Athanasiou, T. (2010) Positive Pre-Resection Pleural Lavage Cytology Is Associated with Increased Risk of Lung Cancer Recurrence in Patients Undergoing Surgical Resection: A Meta-Analysis of 4450 Patients. Thorax, 67, 526-532. http://dx.doi.org/10.1136/thoraxjnl-2011-200424

[9] Tomita, M., Shimizu, T., Matsuzaki, Y., Hara, M., Ayabe, T. and Onitsuka, T. (2005) Prognostic Significance of Carcinoembryonic Antigen Level in Pleural Lavage Fluid for Patients with Lung Adenocarcinoma. The Annals of Thoracic Surgery, 80, 276-281. http://dx.doi.org/10.1016/j.athoracsur.2005.01.028

[10] Satoh, Y., Hoshi, R., Ishikawa, Y., Horai, T., Okumura, S. and Nakagawa, K. (2007) Recurrence Patterns in Patients with Early Stage Non-Small Cell Lung Cancers Undergoing Positive Pleural Lavage Cytology. The Annals of Thoracic Surgery, 83, 197-202. http://dx.doi.org/10.1016/j.athoracsur.2006.08.025

[11] Kawachi, R., Nakazato, Y., Masui, K., Takei, H., Koshi-ishi, Y. and Goya, T. (2009) Clinical Significance of Pleural Lavage Cytology for Non-Small Cell Lung Cancer: Is Surgical Resection Valid for Patients with Positive Pleural Lavage Cytology? Interactive Cardiovascular and Thoracic Surgery, 9, 265-268. http://dx.doi.org/10.1510/icvts.2009.202010

[12] Grunnet, M. and Sorensen, J.B. (2012) Carcinoembryonic Antigen (CEA) as Tumor Marker in Lung Cancer. Lung Cancer, 76, 138-143. http://dx.doi.org/10.1016/j.lungcan.2011.11.012

[13] Tomita, M., Shimizu, T., Hara, M., Ayabe, T. and Onitsuka, T. (2008) Serum Carcinoembryonic Antigen Level and Pleural Lavage Cytology in Woman with Non-Small Cell Lung Cancer. The Thoracic and Cardiovascular Surgeon, 56, 422-425. http://dx.doi.org/10.1055/s-2008-1038781

[14] Tsutani, Y., Yamashita, Y., Misumi, K., Ikeda, T., Miyata, Y. and Okada, M. (2012) Non-Small-Cell Lung Cancer Prognosis Using Carcinoembryonic Antigen Levels in Pleural Lavage Fluid. European Journal of Cardiothoracic Surgery, 42, e96-e101. http://dx.doi.org/10.1093/ejcts/ezs466

[15] Wada, H., Fukuse, T. and Hitomi, S. (1995) Long-Term Survival of Surgical Cases of Lung Cancer. Lung Cancer, 13, 269-274. http://dx.doi.org/10.1016/0169-5002(95)00499-8

[16] Lee, C.K., Brown, C., Gralla, R.J., Hirsh, V., Thongprasert, S., Tsai, C.M., Tan, E.H., Ho, J.C., Chu, D.T., Zaatar, A., Osorio Sanchez, J.A., Vu, V.V., Au, J.S., Inoue, A., Lee, S.M., Gebski, V. and Yang, J.C. (2013) Impact of EGFR Inhibitor in Non-Small Cell Lung Cancer on Progression-Free and Overall Survival: A Meta-Analysis. Journal of the National Cancer Institute, 105, 595-605. http://dx.doi.org/10.1093/jnci/djt072 